Systematic Review

\title{
Tibial tubercle osteotomy for patellofemoral malalignment and chondral disease provided good outcomes: A systematic review
}

\author{
Federica Rosso, MD ", Roberto Rossi, MD, Umberto Cottino, MD, Davide E. Bonasia, MD \\ AO Ordine Mauriziano, Department of Orthopedics and Traumatology, Largo Turati 62, Torino, 10128, Italy
}

\section{A R T I C L E I N F O}

\section{Keywords:}

Knee patella

Osteotomy

Tibial Tubercle

Patellofemoral chondral damage

\begin{abstract}
A B S T R A C T
Importance: Tibial tubercle osteotomy (TTO) is indicated to treat patellofemoral (PF) malalignment and chondral disease refractory to conservative treatment. However, there are no systematic reviews describing TTO outcomes in chondral damages without instability.

Aim: The aims of this study were to (1) assess the quality of the published studies, (2) identify indication for TTO to treat PFP with chondral disease without instability, (3) evaluate the most common TTO techniques, (4) evaluate the clinical outcomes, and (5) evaluate TTO's complication and failure rates.

Evidence review: In December 2020, a literature search was performed applying the following criteria: (1) peerreviewed Level 1-4 studies; (2) English language; (3) human subjects with clinical and/or radiological outcomes; (4) TTO alone or associated with minor cartilage procedure (only drilling, no instability); (5) minimum follow-up 12 months, minimum 10 patients; and (6) no more than $20 \%$ of drop-out rate. Data from studies were collected and described with weighted averages and standard deviations.

Findings: A total of 18 Level 4 studies were included. The average Coleman Methodology Score was 61.5 points (range 48-81). A total of 851 patients (892 knees) were included, with $64.8 \%$ of female patients. The weighted average follow-up was 49.1 months (range 12-128.5). Indication for TTOs was poorly described. The main technique used was anteromedialisation (60.4\%). In $27.7 \%$ of the cases, TTO was associated with lateral release. Different scoring systems were used to evaluate outcomes, with significant improvements. The average rate of good/excellent results was 78.7\% (range 57\%-100\%). Fifteen studies described the complication rate (9.9\%), whereas only four reported the failure rate $(6.2 \%)$.

Conclusion and relevance: TTOs performed to treat PF malalignment associated with chondral disease without instability provided good clinical outcomes, with acceptable complication/failure rates. However, high-level studies are necessary because of studies' heterogeneity regarding patellofemoral malalignment and chondral disease treatment.

Study design and level of evidence: Systematic review. Level IV.

Level of the study: Level IV, systematic review of Level IV studies.
\end{abstract}

\section{Introduction}

Patellofemoral pain (PFP) includes a wide spectrum of conditions, such as patellofemoral malalignment, dysplasia, instability, chondromalacia and arthritis. PFP is commonly treated conservatively with exercise programmes with the aim to treat the factors associated with is development, such as trunk mechanics, excessive hip adductor strength and abductor weakness leading to dynamic valgus, vastus medialis and lateralis imbalance, PF dysplasia, abnormal patellar height, abnormal tibial or femoral rotation, valgus malalignment of the lower limb, gait impairments and rearfoot eversion [1]. In cases unresponsive to conservative treatment, with underlying PF malalignment and/or chondral damages, surgery may be considered, including distal realignments (i.e. Tibial Tubercle Osteotomy [TTO]). The goal of TTO is to improve PF contact area and decrease PF forces [2]. Different types of osteotomies have been described (Fig. 1). Maquet described a pure anteriorisation osteotomy to treat degeneration of the PF joint decreasing PF contact pressure [3]. Other authors proposed pure medialisation techniques for TTO, reducing the Tibial Tubercle-Trochlear Groove (TT-TG) distance, but it is indicated mainly in case of PF instability [4]. In 1983, Fulkerson

\footnotetext{
* Corresponding author. Tel.: +39 011 5082317; Fax: +30 0115082050.

E-mail addresses: federica.rosso@yahoo.it (F. Rosso), rossir@fastwebnet.it (R. Rossi), umberto.cottino@gmail.com (U. Cottino), davidebonasia@virgilio.it (D.E. Bonasia).
} 


\section{What is already known}

- Patellofemoral pain with chondral disease is a common and challenging problem. Many aspects of this pathology are still poorly understood, including aetiology, imaging needed for the diagnosis and most reliable surgical treatments.

- Tibial tubercle osteotomy (TTO) has been proposed to treat chronic anterior knee pain refractory to conservative treatment in association to patellofemoral malalignment, chondral damage and/or excessive lateral patellar tilt-subluxation, with the goal of improving patellofemoral contact area and decreasing patellofemoral forces.

- Despite the overall good results reported in the literature for TTO, several authors described a concerning rate of failures, ranging from $30 \%$ to $70 \%$. However, in most of these studies, TTO's outcomes in patellofemoral chondral disease or instability are evaluated together, and this may be a bias for data interpretation.

described a procedure with anteromedialisation (AMZ) of the tibial tubercle through an oblique osteotomy to treat PFP associated with chondral disease [5].

Clinical outcomes of TTOs performed to treat chondral lesion are strictly related to patient's selection and patellar disease's location. Pidoriano et al. in their retrospective study concluded that AMZ TTO is more effective in distal and lateral facet chondral lesion compared with medial, central or diffuse disease, with $87 \%$ of satisfied patients [2]. However, Farr et al. demonstrated that in the case of proximal or diffuse disease, AMZ TTO associated with autologous chondrocyte implantation may lead to better outcomes compared to TTO alone [6]. Furthermore, it is well known that PF malalignment and chondral disease is a multifactorial pathology, and different factors, such as patellar and trochlear morphology, may play a role in affecting the outcomes of TTO alone in these patients. However, few studies evaluated factors related to outcomes in TTOs for PF chondral disease, but no association with patellar or trochlear morphology was recognised [7-10].

Most of the studies described a relatively low complication rate, ranging between $4 \%$ and $7 \%$, with $1-3 \%$ risk of tubercle fracture, $1 \%$ rate of nonunion and $4 \%$ rate of deep venous thrombosis. However, painful screws requiring removal occur in $3-77 \%$ of cases, with a high rate of reoperations for this reason [11,12]. Furthermore, several authors described a concerning rate of failures, ranging from $30 \%$ to $70 \%$ [13], even if mostly associated with Maquet procedure because of increased skin and compartment tension.

Because of these conflicting results, it is still unclear if TTO alone can be effective in treating PF chondral disease associated with maltracking, even if its effectiveness in reducing contact PF contact pressures has been demonstrated [14]. Few systematic reviews have been previously published on TTO outcomes, but they included both TTO performed for chondral disease or instability, so conclusions are difficult to be drawn $[12,15]$.

The goal of this systematic review was to clarify the role of TTO performed to treat PF maltracking and chondral disease without instability. Particularly, the aims were to (1) assess the quality of the published studies; (2) identify the indication for TTO to treat PFP with chondral disease, excluding TTOs performed to treat PF instability; (3) evaluate the most common TTO techniques; (4) evaluate the clinical outcomes of TTOs performed to treat PF chondral disease; (5) evaluate the complication and failure rates associated with TTO in these patients.

\section{Material and methods}

In December 2020, a literature search following the Preferred Reporting Items for Systematic Reviews and Meta-Analyses guidelines was performed to identify all the studies describing the clinical or

\section{What are the new findings}

- The main aim of this study was to evaluate indication, surgical technique and outcomes of TTO performed to treat PFP associated with chondral disease without PF instability.

- There was no agreement regarding the indications for TTO to treat patellofemoral chondral disease. Few studies described the presence of malalignment (increased Q angle or abnormal Tibial Tubercle-Throclear Groove distance) as a requirement to perform TTO. Furthermore, few studies described the degree of cartilage degeneration (according to the Outerbridge classification) that should be accepted to indicate TTO.

- In $60 \%$ of the patients, an anteromedialisation (AMZ) TTO was performed. Most of the osteotomies were fixed using bi-cortical screws. Lateral release was associated to TTO in less than $27.7 \%$ of the patients. In more than $16 \%$ of the cases, a minor cartilage procedure (i.e. microfracture and shaving) was associated to TTO.

- There was no agreement regarding the postoperative regimen. However, most of the studies allowed immediate full weightbearing with a brace locked in extension during ambulation, and full range of motion (ROM) exercises 4-8 weeks after surgery. Some degrees of ROM were sometimes allowed since the first postoperative week to reduce the risk of stiffness, but there was no agreement in defining a safe cutoff value for early ROM.

- Clinical outcomes were mostly described using not validated, heterogeneous scores, so that a pooled analysis was not feasible. However, despite different scoring systems, the rate of good to excellent results was close to $79 \%$.

- The average complication rate was $9.9 \%$, with infection and stiffness being the most frequent complications. Only four studies described the failure rate, with a weighted average rate of $6.2 \%$.

- TTO to treat PF chondral disease seems to provide good clinical outcomes and acceptable complication/failure rates. However, high-quality studies, with homogeneous methods are required to precisely determine ideal candidates for TTO, most reliable surgical techniques and outcomes.

radiological outcomes of TTO for PFP and/or chondral damage.

The keywords used for the search included "Patellofemoral pain", "Tibial Tubercle Osteotomy", "Fulkerson osteotomy", "Elmsie-Trillat osteotomy", "Maquet osteotomy", "Clinical outcome", "Results" and "Surgical treatment" alone and in various combinations using the Boolean operator "AND" or "OR".

Inclusion criteria were (1) peer-reviewed Level 1 to 4 studies, (2) English language, (3) human subjects with clinical and/or radiological outcomes, (4) patients affected by PFP and/or malalignment associated with chondral disease and indicated for TTO as surgical treatment, (5) TTO alone or in combination with minor procedures (i.e. lateral release or cartilage drilling), (6) minimum 12 months of average follow-up, (7) minimum 10 patients and (8) no more than $20 \%$ of patients lost to followup. Studies involving patients affected by patellar dislocation or instability or TTO associated with major procedures (e.g. major cartilage procedure, Medial Patellofemoral Ligament reconstruction...) were excluded.

The initial search identified 50,234 articles. All these titles were screened by two authors as described in Fig. 2. Applying the previously mentioned criteria, 18 studies were included in this systematic review. No studies revealed overlapping case series.

The Coleman Methodology score was calculated by an independent reviewer to evaluate the methodological quality [16]. Different data were extracted from the studies and collected on an Excel (Microsoft, Redmond, WA) worksheet. Particularly, all data regarding demographics, clinical and radiological preoperative evaluation, surgical treatment, postoperative protocols, outcomes, complications and failures were recorded. Data are reported with weighted average and ranges or 

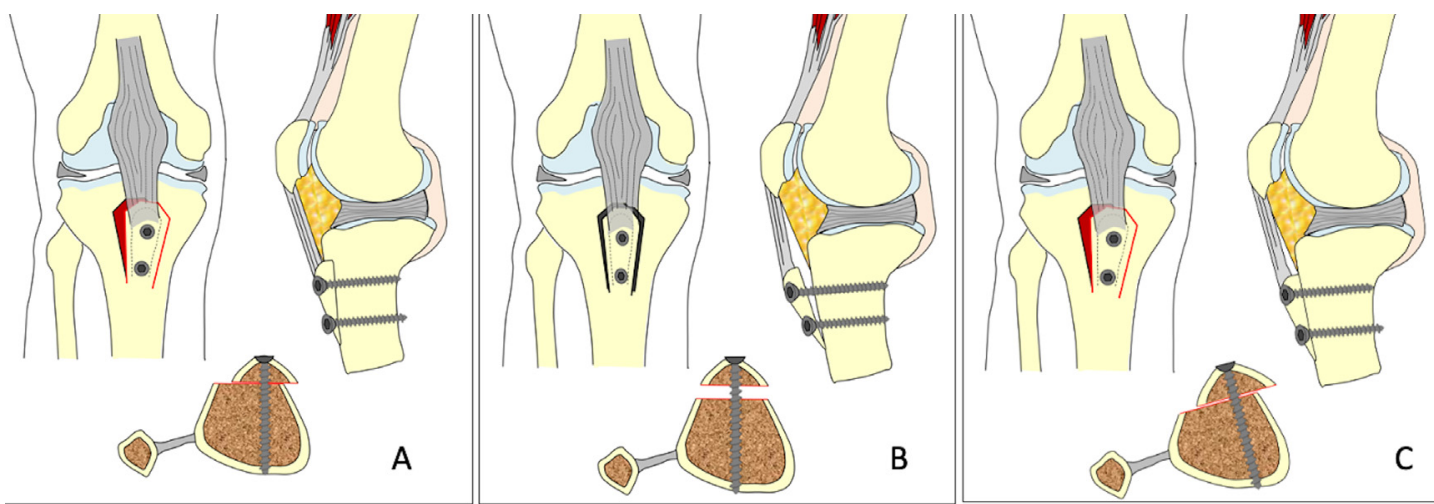

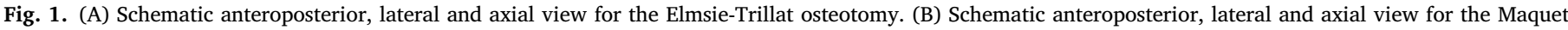
osteotomy. (C) Schematic anteroposterior, lateral and axial view for the Fulkerson osteotomy.

standard deviation (SD).

\section{Results}

\section{Description of studies}

All 18 studies included in the review were classified as Level 4 according to Wright et al. [17]. The average Coleman Methodology Score [16] was 61.5 points (range 48-81).

\section{Demographic data}

This systematic review included 851 patients ( 892 knees). There were 283 male $(35.2 \%)$ and 522 female (64.8\%) patients. Two studies did not describe the gender distribution (46 patients) [3,18]. The weighted average age at the time of surgery was 36.2 years (range $22.5-56$ years). Seven studies reported the number of previous surgical procedures $(94.4$ procedures in 408 cases, 23.1\%) [19-24]. The weighted average follow-up was 49.1 months (range 12-128.5), and the weighted average follow-up rate was $95.9 \%$ (range $83 \%-100 \%$ ).

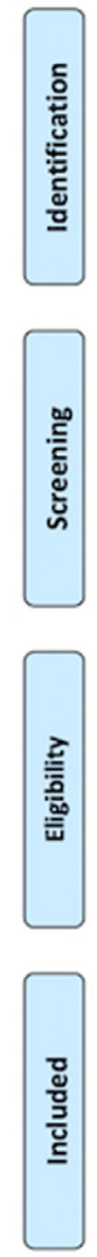

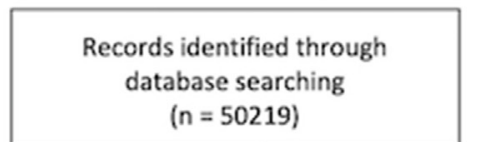

$(n=50219)$
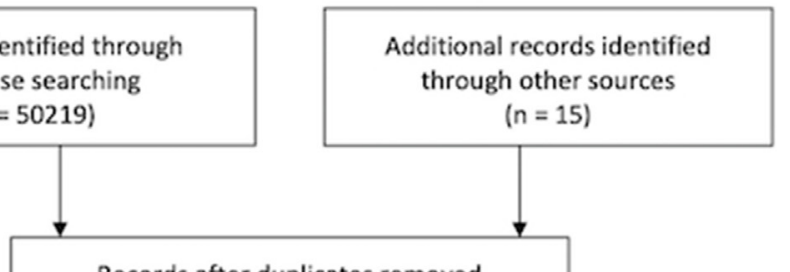

Records after duplicates removed ( $n=1256$ )

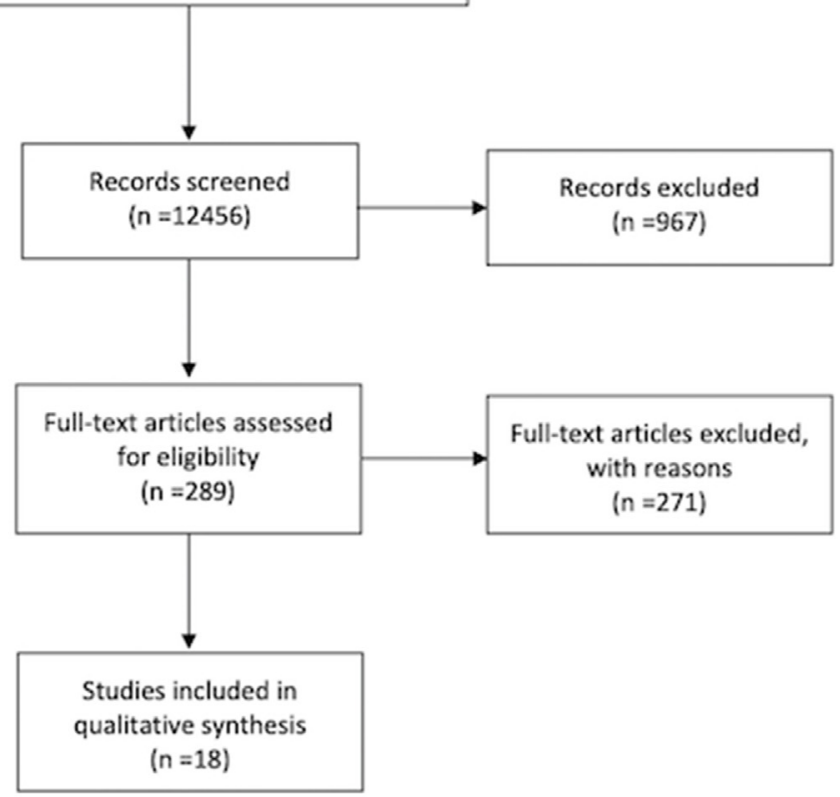

Fig. 2. Diagram showing the selection process according to the PRISMA guidelines. 
In all studies, the indication for surgery was chronic anterior knee pain. Twelve studies reported as main indication persistent anterior knee pain after 6-12 months of conservative treatment, including quadriceps and hamstrings muscle stretching, closed chain exercises, vastus medialis and lateralis as well as hip muscles strengthening and core balancing [7-10,13,19-23,25,26]. Two studies reported the presence of lateral patellar tracking as a prerequisite for surgery, but they did not specify how it was evaluated $[18,24]$. Four studies reported a pathologic Q angle as a mandatory requirement to indicate surgery $[9,10,19,20]$. Only two studies described the presence of a TT-TG distance $>15 \mathrm{~mm}$ as a mandatory requirement for TTO $[9,22]$. These data are summarised in Table 1.

Table 1

Demographic data of the studies.

\begin{tabular}{|c|c|c|c|c|c|c|c|c|}
\hline Author & Year & $\begin{array}{l}\text { Num of TTOs } \\
\text { reviewed/Tot } \\
\text { TTOs performed }\end{array}$ & $\begin{array}{l}\text { Mean age } \\
\text { (range) }\end{array}$ & $\begin{array}{l}\text { Male/female } \\
\text { (Tot patients) }\end{array}$ & $\begin{array}{l}\text { Follow-up } \\
\text { (range) }\end{array}$ & $\begin{array}{l}\text { Follow- } \\
\text { up rate }\end{array}$ & Level & Indications for surgery \\
\hline Bellemans [19] & 1997 & $29 / 29$ & 26 y (18-42) & $12 / 17$ (29) & $32 \mathrm{~m}(25-44)$ & $100 \%$ & 4 & $\begin{array}{l}\text { - Chronic anterior knee pain unresponsive } \\
\text { to } 1 \text { year of conservative treatment } \\
\text { - Pathologic } Q \text { angle } \\
\text { - No dislocation } \\
\text { - Pain free medial patellar facet } \\
\text { - No previous surgery }\end{array}$ \\
\hline Cameron [20] & 1986 & $44 / 53$ & 40.4 y (19-71) & $20 / 33(53)$ & Minimum 12 months & $83 \%$ & 4 & $\begin{array}{l}\text { - Chronic anterior knee pain not responsive } \\
\text { to conservative treatment } \\
\text { - Patellofemoral malalignment (Q angle) }\end{array}$ \\
\hline Engebretsen [13] & 1989 & $41 / 46$ & 32.6 y (23-55) & $24 / 14(38)$ & $64.8 \mathrm{~m}(36-108)$ & $89.1 \%$ & 4 & $\begin{array}{l}\text { - Chronic anterior knee pain not responsive } \\
\text { to } 1 \text { year of conservative treatment } \\
\text { - No other than chondromalacia }\end{array}$ \\
\hline Ferguson [29] & 1982 & $144 / 144$ & 38.6 y (16-76) & $55 / 89(144)$ & $24 \mathrm{~m}$ (NR) & $100 \%$ & 4 & $\begin{array}{l}\text { - Chronic anterior knee pain not responsive } \\
\text { to } 1 \text { year of conservative treatment } \\
\text { - Loss of function }\end{array}$ \\
\hline Fulkerson [25] & 1990 & $30 / 31$ & 28 y $(14-56)$ & $6 / 24(30)$ & $35 \mathrm{~m}(26-50)$ & $96.8 \%$ & 4 & $\begin{array}{l}\text { - Chronic anterior knee pain not responsive } \\
\text { to conservative treatment } \\
\text { - Significant patellofemoral malalignment } \\
\text { causing persistent pain that had }\end{array}$ \\
\hline Hejgaard [26] & 1982 & $20 / 20$ & 28 y $(18-38)$ & $10 / 10(20)$ & $12 \mathrm{~m}(0)$ & $100 \%$ & 4 & $\begin{array}{l}\text { - Chronic anterior knee pain not responsive } \\
\text { to conservative treatment for at least } 6 \text { months } \\
\text { - No pathologic morphology of patellofemoral } \\
\text { joint } \\
\text { - Outerbridge } 1 \text { to } 3\end{array}$ \\
\hline Jack [7] & 2012 & $50 / 51$ & 34.4 y $(19.6-52.2)$ & $7 / 39(46)$ & $72.6 \mathrm{~m}(62-118)$ & $98 \%$ & 4 & $\begin{array}{l}\text { - Persistent anterior knee pain that was } \\
\text { interfering with daily activities }\end{array}$ \\
\hline Jenny [8] & 1996 & $100 / 100$ & 43 y (17-64) & $46 / 54(100)$ & $48 \mathrm{~m}(24-96)$ & $100 \%$ & 4 & $\begin{array}{l}\text { - Chronic anterior knee pain not responsive } \\
\text { to conservative treatment for at least } \\
6 \text { months }\end{array}$ \\
\hline Karlsson [21] & 1985 & $72 / 75$ & 29 y $(16-51)$ & $28 / 47(75)$ & $30 \mathrm{~m}(12-60)$ & $96 \%$ & 4 & $\begin{array}{l}\text { - Chronic anterior knee pain not responsive } \\
\text { to conservative treatment for at least } 1 \text { year }\end{array}$ \\
\hline Koeter [18] & 2007 & $30 / 30$ & 26 y (18-37) & Not reported & $24 \mathrm{~m}(\mathrm{NR})$ & $100 \%$ & 4 & $\begin{array}{l}\text { - Chronic anterior knee pain not responsive } \\
\text { to conservative treatment for at least } 1 \text { year } \\
\text { - TT-TG }>15 \mathrm{~mm}\end{array}$ \\
\hline Liu [22] & 2017 & $61 / 61$ & 29.6 y (NR) & $9 / 48(57)$ & $55.2 \mathrm{~m}(\mathrm{NR})$ & $100 \%$ & 4 & $\begin{array}{l}\text { - Failed nonoperative treatment } \\
\text { (at least } 6 \text { months) } \\
\text { - Patellofemoral pain and/or arthritis } \\
\text { (lateral or inferior) } \\
\text { - Younger than } 40 \text { years }\end{array}$ \\
\hline Maquet [3] & 1976 & $37 / 39$ & 56 y $(19-81)$ & Not reported & $56.4 \mathrm{~m}(12-120)$ & $94.9 \%$ & 4 & - Patellofemoral arthritis or chondromalacia \\
\hline Morshuis [23] & 1990 & $20 / 25$ & 36 y $(18-66)$ & $11 / 11(21)$ & $30.4 \mathrm{~m}(22-38)$ & $90.9 \%$ & 4 & $\begin{array}{l}\text { - Chronic anterior knee pain not responsive } \\
\text { to conservative treatment for at least } 1 \text { year } \\
\text { - Patellofemoral arthritis }\end{array}$ \\
\hline Radin [24] & 1993 & $42 / 42$ & 31 y (16-49) & $24 / 15(39)$ & $73.2 \mathrm{~m}(36-117.6)$ & $100 \%$ & 4 & - Patellofemoral osteoarthritis or malalignment \\
\hline Rosso [9] & 2018 & $78 / 85$ & 43.5 y (NR) & $17 / 52(69)$ & $67.9(24-163)$ & $91.8 \%$ & 4 & $\begin{array}{l}\text { - Isolated patellofemoral pain with chondral } \\
\text { disease } \\
\text { - Age } 18-65 \text { years } \\
\text { - Less than grade } 3 \text { Kellegren-Lawrence } \\
\text { - Failure of at least } 6 \text { months of nonoperative } \\
\text { treatment }\end{array}$ \\
\hline Sakai [27] & 1996 & $21 / 21$ & 50 y (47-65) & $1 / 15(16)$ & $60 \mathrm{~m}(48-156)$ & $100 \%$ & 4 & $\begin{array}{l}\text { - Patellar pain } \\
\text { - Narrowing of patellar joint space }<3 \mathrm{~mm} \\
\text { - Lateralisation of more than } 5 \mathrm{~mm} \text { at } 30^{\circ} \\
\text { of knee flexion } \\
\text { - More than } 15^{\circ} \text { of lateral tilt at skyline view }\end{array}$ \\
\hline Shelbourne [28] & 1994 & $11 / 11$ & 22.5 y (15-39) & $3 / 8(11)$ & $48 \mathrm{~m}(6-36)$ & $100 \%$ & 4 & $\begin{array}{l}\text { - Patellofemoral pain syndrome associated } \\
\text { to malalignment } \\
\text { - No instability }\end{array}$ \\
\hline Wang [10] & 2014 & $62 / 72$ & 45.7 y $(22-74)$ & $10 / 46(56)$ & 128.5 m (116-149) & $86.1 \%$ & 4 & $\begin{array}{l}\text { - Progressive pain and functional disability } \\
\text { with failure to at least } 6 \text { months of } \\
\text { conservative treatment } \\
\text { - Pathologic Q angle }\end{array}$ \\
\hline
\end{tabular}

TTO = Tibial Tubercle Osteotomy; Num = Number; Tot $=$ Total; TT-TG $=$ Tibial Tubercle-Trochlear Groove, NR $=$ not reported. 


\section{Preoperative assessment}

Seven studies evaluated the preoperative patellar tilt angle $[7,9,18,19$, $23,26,27]$, but only three studies (128 knees) reported the values, with a weighted average of $11.6^{\circ}$ (SD 1.7) $[9,19,27]$. Seven studies evaluated the congruence angle $[7,9,10,18,19,26,28]$, but only three studies (118 knees) $[9,19,28]$ reported the values, with a weighted average of $17.5^{\circ}$ (SD 7.4). Three studies described the patellar height using the Insall-Salvati ratio $[9,10,23]$, but only Wang et al. (62 cases) reported the value, with an average of 1.09 (SD 0.1) [10]. Two studies described the patellar height using the Caton index (91 cases), with an average of 1 (range 0.7-1.5) [18,22]. The preoperative TT-TG distance was evaluated in three studies (169 knees) [9,18,22], with a weighted average of $15.9 \mathrm{~mm}$ (SD 2.1). Five studies described the preoperative $\mathrm{Q}$ angle $[9,10$, $19,25,26]$, but only two studies (92 cases) reported the values, with a weighted average of $18.9^{\circ}$ (SD 2.8) [10,25]. Six studies described the Outerbridge arthroscopic classification of chondral disease in 323 cases $[7,8,13,21,22,26]$. Of these cases, $20.7 \%$ were classified as Outerbridge grade I, $22.9 \%$ as grade II, $27.9 \%$ as grade III and $28.5 \%$ as grade IV.

\section{Surgical techniques}

Anteriorisation TTO was performed in six studies (312 cases, 35\%) [3, $8,13,21,24,26]$, medialisation TTO in two studies (41 cases, 4.6\%) [3,18] and anteromedialisation TTO in the remaining 10 studies (539 knees, $60.4 \%)[7,9,10,19,20,22,23,25,27,29]$. The osteotomy was fixed using either screws or bone grafts. In 14 studies, fixation was achieved with one, two or three screws, for a total of 628 cases (70.4\%) [7-10,18-23, 25-28]. However, few studies described in detail the type of screw used, including two studies (80 cases) using two $3.5 \mathrm{~mm}$ cortical screws [7,18], one study (11 knees) using two $4 \mathrm{~mm}$ cancellous screws [28] and two studies (138 knees) using two $4.5 \mathrm{~mm}$ cortical screws [9,22].

In four papers, a bone graft from the anterior iliac crest was used to stabilise the osteotomy for a total of 264 knees (29.6\%) [3,13,24,29]. In $3 / 4$ of the studies using bone grafts (120 cases), a pure anteriorisation TTO was performed [3,13,24]. Six studies (328 cases) described the amount of anteriorisation obtained $[8,10,13,21,25,26]$, for a weighted average of $1.3 \mathrm{~cm}$ (range 1-1.59 cm). However, only one study (62 cases) reported the average medialisation obtained, equal to $9.2 \mathrm{~mm}$ (range 0-15 mm) [10]. In seven studies, TTO was associated with lateral release, for a total of 247 cases $(27.7 \%$ of the total) $[9,10,19,20,22,27,28]$. In six studies (143 cases, $16 \%$ of the total) $[8,13,20-22,26]$, TTO was associated with minor cartilage procedures, including cartilage shaving (105 cases, $73.4 \%$ of all associated procedures) or drilling (39 cases, $27.3 \%$ of all associated procedures). Table 2 summarises these data.

\section{Postoperative regimen and rehabilitation}

There was no agreement between the studies regarding postoperative protocol after TTO.

Six studies did not adequately describe postoperative protocol, for a total of $252 / 892$ cases $(28.2 \%)$ [3,13,18,21,24,25]. The postoperative regimen was adequately described in 12 studies (587 cases). In seven of these studies, immediate weight-bearing was allowed (456/587 cases, $77.7 \%$ ) [7-9,20,23,26,29]. In the remaining five studies (131/587 cases, $22.3 \%$ ), full weight-bearing was allowed 2-9 weeks after surgery $[10,19$, $22,27,28]$. Immediate or delayed weight-bearing was not related to the type of fixation used (screws or bone graft). Immediate full ROM (first or second weeks) was allowed in five studies (192/640 cases, 30\%) [9,10, 26-28]. In seven studies (403/640 cases, $62.9 \%$ ), full ROM was started 4-8 weeks after surgery $[7,8,19,20,22,23,29]$. In four studies (150 cases), the authors used continuous passive motion in the immediate postoperative period [18,19,22,25]. Twelve studies used different types of postoperative immobilisation (679 cases) for a weighted average of 5.5 weeks (range 3-8 weeks), including a removable walking cast or splint (10 studies, 495/679 cases, 72.9\%) [7-10,19,20,22,25,28] and a not removable cast (two studies, 164/679 cases, 24.1\%) [23,29]. Table 2 summarises these data.

\section{Clinical and radiological outcomes}

Many different scores were used to evaluate the outcomes of TTO. The visual analogue scale for pain and/or overall knee function was used in two studies (80 knees) $[7,18]$. The Lysholm score [30] was evaluated pre- and post-operatively in five studies, including 192/892 cases (21.5\%) [10,13,18,19,25]. Seven studies [5,7,9,10,18,19,22] reported the pre- and post-operative Kujala score [31], for a total of 340/892 cases $(38.1 \%)$. Other scores were used in the remaining studies. Nine studies (449/892 knees, 50.3\%) described the outcomes using a not validated score based on pain, subjective or objective results, alone or in association with a validated score [3,8,20,24,26-29]. An improvement in the postoperative period was reported in all studies. The weighted average Lysholm score was 60.5 points (range 41.3-71.1) preoperatively and 84.1 points (range 56.2-92) at the last follow-up (192/892 cases). Similarly, the Kujala score improved from a weighted preoperative average of 45.5 points (range $39.2-62$ ) to 79.6 points at the last follow-up (range 57.7-90; 340/892 cases). Twelve studies (509/892 knees, 57.1\%) reported the outcomes divided into excellent, good, poor or fair, based on the main clinical score used [3,5,7,8,10,20,21,24,26-28]. The resulting average rate of excellent or good results was $78.7 \%$ (range $57 \%-100 \%$ ). Fig. 3 shows the average percentages divided into the subgroups.

Six of these studies (227 cases) [7,10,20,23,25,27] reported on AMZ TTOs with an average rate of good/excellent outcomes in $79.8 \%$ of the cases. On the other hand, five studies (271 cases) $[8,21,24,26]$ reported on pure anteriorisation TTOs, with a rate of $73 \%$ of good/excellent results. Although AMZ TTO seemed to obtain better outcomes, the two groups of studies were heterogeneous in terms of gender and age distribution $(p>0.05)$, and therefore, a statistical analysis was not possible. Six studies (266 knees) [7,10,13,22,23,25] reported the overall satisfaction rate, with a weighted average of $71.3 \%$ of satisfied patients (range 30.3\%-93.3\%).

Few studies described the radiological outcomes of TTO. In particular, two studies reported on postoperative patellar tilt (107 cases; average $7.8^{\circ}$ ) $[9,19]$, three studies described the postoperative congruence angle (118 knees; average $9.5^{\circ}$ ) [9,19,28], and two other studies reported on the postoperative patellar height (average Caton index in one study 1.03; average Insall-Salvati index in one study 0.87) $[10,18]$.

\section{Complications and failures}

Three studies did not report the complications of TTO [27,28,31]. In the remaining studies (830 cases), 82 complications were reported (9.9\%; Table 2). The most common complications were postoperative stiffness (25.6\% of all complications), superficial and deep infection $(22 \%)$, effusion $(11 \%)$, fracture of the tuberosity $(7.3 \%)$, and deep venous thrombosis $(7.3 \%)$. Less common complications included nonunion (6\%) and skin necrosis (3.6\%). Eight rare complications were also described (9.7\%), including peroneal nerve palsy, complex regional pain syndrome, and neuroma. Skin necrosis was described only in studies regarding pure anteriorisation techniques [3,21]. Eight studies, including 323 knees, described a weighted average rate of hardware removal of $44 \%$ (range $11.6 \%-96 \%$ ) [7,9,10,22,23,26-28]. Only four studies [9,20, $24,25]$ reported the number of failures, described with the following endpoints: patellectomy, patellofemoral replacement, revision surgery or need for total knee arthroplasty. In these four studies (194 knees), 12 failures $(6.2 \%)$ were reported. No studies reported the cumulative survivorship after TTO. Failure rates are summarised in Table 2.

\section{Discussion}

The first aim of the present review was to assess the quality of the published studies. All studies included were defined as Level IV case 
Table 2

Summary of surgical data, outcomes, complications and failures.

\begin{tabular}{|c|c|c|c|c|c|c|c|c|c|c|}
\hline Author & Chondral damage & Type of osteotomy & $\begin{array}{l}\text { Fixation } \\
\text { method }\end{array}$ & $\begin{array}{l}\text { Concurrent } \\
\text { procedures }\end{array}$ & Postoperative care & Scoring system & Outcomes & $\begin{array}{l}\text { Hardware } \\
\text { removal }\end{array}$ & $\begin{array}{l}\text { Overall } \\
\text { complication } \\
\text { rate }\end{array}$ & $\begin{array}{l}\text { Failure } \\
\text { rate }\end{array}$ \\
\hline $\begin{array}{l}\text { Bellemans } \\
\text { [19] }\end{array}$ & Not reported & Anteromedialisation & Screws & $\begin{array}{l}51.7 \% \text { associated } \\
\text { LR }\end{array}$ & $\begin{array}{l}\text { No weight-bearing and } \\
\text { hinged knee brace for } \\
8 \text { weeks }\end{array}$ & $\begin{array}{l}\text { Lysholm and Kujala } \\
\text { score }\end{array}$ & $\begin{array}{l}\text { All scores improved. No nonunion. } \\
1 \text { proximal tibial fracture }\end{array}$ & $\begin{array}{l}\text { Not } \\
\text { reported }\end{array}$ & $3.4 \%$ & $\begin{array}{l}\text { Not } \\
\text { reported }\end{array}$ \\
\hline $\begin{array}{l}\text { Cameron } \\
{[20]}\end{array}$ & Not reported & Anteromedialisation & Screws & $\begin{array}{l}\text { LR performed in all } \\
\text { the cases }\end{array}$ & $\begin{array}{l}\text { Immediate weight- } \\
\text { bearing. Plastic } \\
\text { walking splint for } 6 \\
\text { weeks }\end{array}$ & Self-rating system & $\begin{array}{l}81.8 \% \text { good to excellent results. } \\
\text { Three failures (patellectomy or } \\
\text { patellofemoral arthroplasty) }\end{array}$ & $\begin{array}{l}\text { Not } \\
\text { reported }\end{array}$ & $\begin{array}{l}18.9 \% \text { (three } \\
\text { deep infection) }\end{array}$ & $6.8 \%$ \\
\hline $\begin{array}{l}\text { Engebretsen } \\
\text { [13] }\end{array}$ & $\begin{array}{l}\text { Outerbridge ( } 6 \mathrm{pt} \\
\text { grade I, } 17 \mathrm{pt} \text { grade } \\
\text { II, } 7 \mathrm{pt} \text { grade III, } \\
7 \mathrm{pt} \text { grade IV) }\end{array}$ & Anteriorisation & $\begin{array}{l}\text { Bone } \\
\text { graft }\end{array}$ & $\begin{array}{l}\text { All cases associated } \\
\text { with cartilage } \\
\text { shaving }\end{array}$ & Not reported & Lysholm and Tegner & $\begin{array}{l}\text { All score improved. } 17 \mathrm{pt} \text { were } \\
\text { unchanged, and } 6 \mathrm{pt} \text { worse than } \\
\text { before surgery. Overall satisfaction } \\
30.3 \%\end{array}$ & $\begin{array}{l}\text { Not } \\
\text { reported }\end{array}$ & $\begin{array}{l}21.2 \%(1 \\
\text { infection })\end{array}$ & $\begin{array}{l}\text { Not } \\
\text { reported }\end{array}$ \\
\hline $\begin{array}{c}\text { Ferguson } \\
{[29]}\end{array}$ & Not reported & Anteromedialisation & $\begin{array}{l}\text { Bone } \\
\text { graft }\end{array}$ & $\begin{array}{l}\text { No associated } \\
\text { procedures }\end{array}$ & $\begin{array}{l}\text { Immediate weight- } \\
\text { bearing. Six weeks of } \\
\text { cast in extension }\end{array}$ & Self-grading & $\begin{array}{l}85 \% \text { of patients resumed the ability } \\
\text { to ascend stairs and could resume } \\
\text { previously lost athletic function }\end{array}$ & $\begin{array}{l}\text { Not } \\
\text { reported }\end{array}$ & $\begin{array}{l}2.1 \% \text { (1 } \\
\text { infection) }\end{array}$ & $\begin{array}{l}\text { Not } \\
\text { reported }\end{array}$ \\
\hline $\begin{array}{l}\text { Fulkerson } \\
\text { [25] }\end{array}$ & Not reported & Anteromedialisation & Screws & Not reported & $\begin{array}{l}\text { Walking brace in } \\
\text { extension for } 4 \text { weeks } \\
\text { (first } 25 \text { patients). } \\
\text { Postoperative CPM }\end{array}$ & Lysholm and Kujala & $\begin{array}{l}93 \% \text { good and excellent results } \\
\text { subjectively and } 89 \% \text { good and } \\
\text { excellent results } \\
\text { objectively. Four subsequent } \\
\text { surgeries due to failure }\end{array}$ & $\begin{array}{l}\text { Not } \\
\text { reported }\end{array}$ & $36.7 \%$ & $13.3 \%$ \\
\hline $\begin{array}{l}\text { Hejgaard } \\
{[26]}\end{array}$ & $\begin{array}{l}\text { Outerbridge }(12 \mathrm{pt} \\
\text { grade I, } 7 \text { pt grade } \\
\text { II, } 1 \text { pt grade III, } \\
0 \text { pt grade IV) }\end{array}$ & Anteriorisation & Screws & $\begin{array}{l}\text { All cases associated } \\
\text { to cartilage } \\
\text { shaving }\end{array}$ & $\begin{array}{l}\text { Immediate weight- } \\
\text { bearing and full ROM }\end{array}$ & Self-grading & $\begin{array}{l}70 \% \text { overall good and excellent } \\
\text { results }\end{array}$ & $90 \%$ & $20 \%$ & $\begin{array}{l}\text { Not } \\
\text { reported }\end{array}$ \\
\hline Jack [7] & $\begin{array}{l}\text { Outerbridge ( } 15 \mathrm{pt} \\
\text { grade I, } 17 \mathrm{pt} \text { grade } \\
\text { II, } 16 \mathrm{pt} \text { grade III, } \\
3 \mathrm{pt} \text { grade IV) }\end{array}$ & Anteromedialisation & Screws & $\begin{array}{l}\text { All isolated } \\
\text { procedures }\end{array}$ & $\begin{array}{l}\text { Immediate weight- } \\
\text { bearing. Splint in } \\
\text { extension for } 3 \text { weeks }\end{array}$ & VAS and Kujala & $\begin{array}{l}\text { All score significantly improved. } \\
86 \% \text { would have surgery again }\end{array}$ & $12 \%$ & $\begin{array}{l}4 \%(1 \\
\text { infection })\end{array}$ & $\begin{array}{l}\text { Not } \\
\text { reported }\end{array}$ \\
\hline Jenny [8] & $\begin{array}{l}\text { Outerbridge }(15 \mathrm{pt} \\
\text { grade I, } 16 \mathrm{pt} \text { grade } \\
\text { II, } 21 \mathrm{pt} \text { grade III, } \\
48 \mathrm{pt} \text { grade IV) }\end{array}$ & Anteriorisation & Screws & $\begin{array}{l}52 \% \text { of minor } \\
\text { cartilage } \\
\text { procedures } \\
\text { combined (shaving } \\
\text { or drilling) }\end{array}$ & $\begin{array}{l}\text { Immediate full weight- } \\
\text { bearing. ROM limited } \\
\text { to } 90^{\circ} \text { for } 3 \text { weeks }\end{array}$ & Pain score & $\begin{array}{l}\text { Pain score significantly improved. } \\
62 \% \text { success rate. Grade IV } \\
\text { chondral damage was associated to } \\
\text { best results }\end{array}$ & $\begin{array}{l}\text { Not } \\
\text { reported }\end{array}$ & $\begin{array}{l}9 \%(5 \\
\text { infection })\end{array}$ & $\begin{array}{l}\text { Not } \\
\text { reported }\end{array}$ \\
\hline Karlsson [21] & $\begin{array}{l}\text { Outerbridge }(15 \mathrm{pt} \\
\text { grade I, } 10 \mathrm{pt} \text { grade } \\
\text { II, } 24 \mathrm{pt} \text { grade III, } \\
7 \mathrm{pt} \text { grade IV) }\end{array}$ & Anteriorisation & Screws & $\begin{array}{l}23.6 \% \text { of } \\
\text { associated minor } \\
\text { cartilage } \\
\text { procedures } \\
\text { (shaving or } \\
\text { drilling) }\end{array}$ & Not reported & $\begin{array}{l}\text { Hejgaard \& Watt- } \\
\text { Boolsen }\end{array}$ & $\begin{array}{l}57 \% \text { of patients improved. } 24 \% \\
\text { poor results }\end{array}$ & $\begin{array}{l}\text { Not } \\
\text { reported }\end{array}$ & $2.8 \%$ & $\begin{array}{l}\text { Not } \\
\text { reported }\end{array}$ \\
\hline Koeter [18] & Not reported & Medialisation & Screws & $\begin{array}{l}16.7 \% \text { medial } \\
\text { retinaculum } \\
\text { reefing }\end{array}$ & $\begin{array}{l}\text { Removable walking } \\
\text { cast for } 6 \text { weeks }\end{array}$ & Vas, Lysholm and Kujala & All scores improved & $\begin{array}{l}\text { Not } \\
\text { reported }\end{array}$ & Not reported & $\begin{array}{l}\text { Not } \\
\text { reported }\end{array}$ \\
\hline Liu [22] & $\begin{array}{l}\text { Outerbridge ( } 4 \text { pt } \\
\text { grade I, } 7 \text { pt grade } \\
\text { II, } 21 \mathrm{pt} \text { grade III, } \\
19 \text { pt grade IV) }\end{array}$ & Anteromedialisation & Screws & $\begin{array}{l}68.4 \% \text { associated } \\
\text { LR }\end{array}$ & $\begin{array}{l}\text { No weight-bearing } \\
\text { hinged brace } 6 \text { weeks. } \\
\text { ROM 0-60 } 2 \text { weeks, } \\
\text { complete ROM in } 6 \\
\text { weeks }\end{array}$ & Kujala and pain score & $\begin{array}{l}\text { All scores improved. 83.3\% } \\
\text { returned to sport }\end{array}$ & $29.5 \%$ & $23 \%$ & $\begin{array}{l}\text { Not } \\
\text { reported }\end{array}$ \\
\hline Maquet [3] & Not reported & Anteriorisation & $\begin{array}{l}\text { Bone } \\
\text { graft }\end{array}$ & $\begin{array}{l}\text { All isolated } \\
\text { procedures }\end{array}$ & Not reported & Self-grading & $\begin{array}{l}\text { Improvement in the score. } 93.7 \% \\
\text { of good to excellent results }\end{array}$ & $\begin{array}{l}\text { Not } \\
\text { reported }\end{array}$ & $2.7 \%$ & $\begin{array}{l}\text { Not } \\
\text { reported }\end{array}$ \\
\hline $\begin{array}{l}\text { Morshuis } \\
\text { [23] }\end{array}$ & Not reported & Anteromedialisation & Screws & $\begin{array}{l}\text { All isolated } \\
\text { procedures }\end{array}$ & $\begin{array}{l}\text { Immediate weight- } \\
\text { bearing, cast for } 6 \\
\text { weeks }\end{array}$ & Trillat score & Satisfactory results in $60 \%$ & $96 \%$ & $15 \%$ & $\begin{array}{l}\text { Not } \\
\text { reported }\end{array}$ \\
\hline Radin [24] & Not reported & Anteriorisation & $\begin{array}{l}\text { Bone } \\
\text { graft }\end{array}$ & $\begin{array}{l}\text { All isolated } \\
\text { procedures }\end{array}$ & Not reported & Self-grading & $\begin{array}{l}79 \% \text { good to excellent results. Six } \\
\text { failures due to social/psychiatric } \\
\text { reasons }\end{array}$ & $\begin{array}{l}\text { Not } \\
\text { reported }\end{array}$ & $\begin{array}{l}7.1 \%(1 \\
\text { infection })\end{array}$ & $7.1 \%$ \\
\hline
\end{tabular}




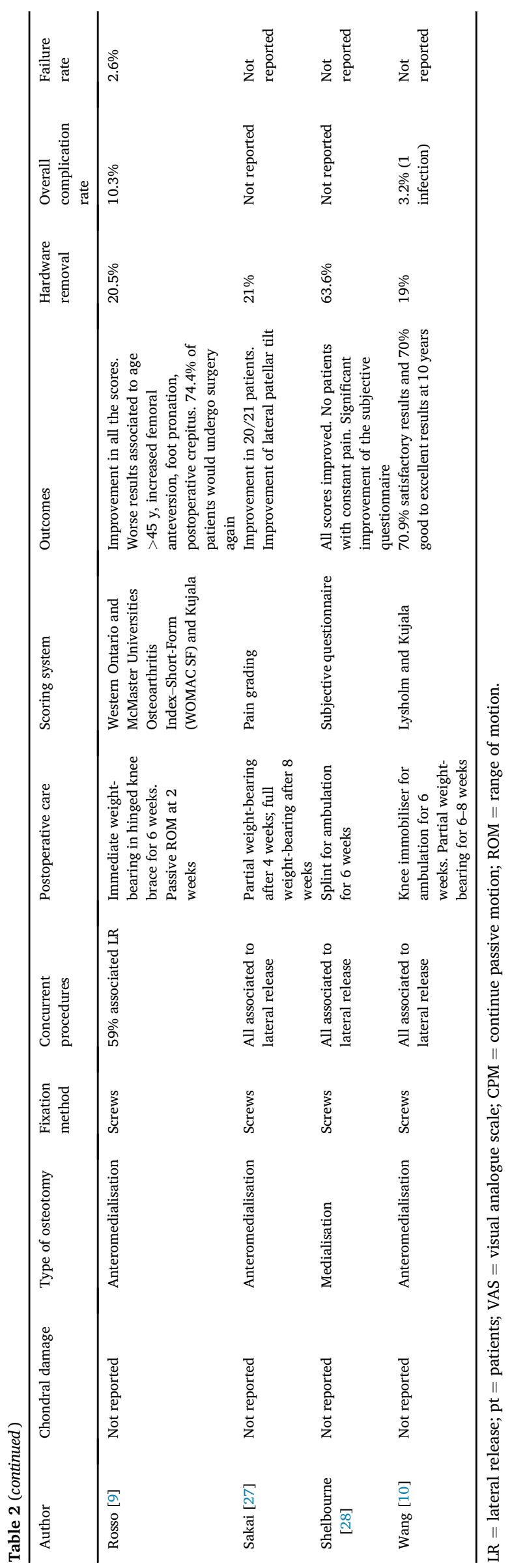

series, according to Wright et al. [17], with a relatively low Coleman Methodology score [16] (61.5 points).

The second aim of this review was to identify the indications of TTO for PF pain and/or chondral damage treatment. No uniformity was found between the studies. However, it should be indicated when symptomatic malalignment or chondral lesions are present and conservative treatments fail. The available literature is not clear about which preoperative examinations should be performed to assess PFP malalignment. An increased Q angle was previously identified as a risk factor for PFP, but only five studies in this review evaluated it $[9,10,19,25,26]$, and only two studies (92 knees) reported the values, for a weighted average of $18.9^{\circ}$ $[10,25]$. A complete radiological preoperative work-up, together with a magnetic resonance imaging and sometimes a computed tomography scan, should be requested. On these examinations, different measurements can be performed, including patellar height, congruence angle, patellar tilt angle, sulcus angle and TT-TG distance. In this systematic review, only three studies evaluated the TT-TG distance [9,18,22], which is generally considered the best measurements to evaluate PF malalignment.

Only six studies (323 patients) reported the degree of chondral disease $[7,8,13,21,22,26]$, with half cases having Outerbridge grade I or II of cartilage degeneration. Some authors described the association between TTO outcomes and degree of cartilage degeneration. Jack et al. did not find any correlation between outcomes and grade of chondromalacia [7]. Jenny et al. in their series described most favourable results in patients with Outerbridge grade IV cartilage lesions [8]. Furthermore, anteromedialisation TTO seems to produce better results when the lesion is located at the inferior pole or lateral facet of the patella according to different in vitro studies, but it is not confirmed from this systematic review [32]. In conclusion, most of the authors agreed that TTO for PFP and chondral disease should be performed in young patients, with mild arthritis (Kellegren-Lawrence < grade III), PF malalignment (abnormal Q angle or TT-TG $>20 \mathrm{~mm}$ ) and at least 6 months of failed conservative treatment.

The third aim of this review was to identify the most performed surgical techniques for TTOs. In this review, anteriorisation (35\%) and AMZ TTOs (60.4\%) were the most common procedures, and this is not surprising because pure medialisation TTOs are indicated in case of instability. Pure anteriorisation is theoretically highly effective in reducing contact pressure on $\mathrm{PF}$ joint. The surgical technique consisted in a TTO performed to obtain a long shingle, which was elevated with a $1-1.5 \mathrm{~cm}$ bone graft normally harvested from the iliac crest. Originally left without any fixation, some authors proposed to fix it with two screws (Fig. 1A) [8,21,24,26]. This tubercle elevation was probably responsible for the high rate of complication and associated skin necrosis. In this systematic review, the high rate of pure anteriorisation TTO is quite surprising, even if it is referred mostly to studies performed in the 80s, when complications related to this technique were still unknown $[3,8,13$, 21,24,26].

In seven studies, TTOs were associated with lateral release (247 cases, $27.7 \%$ of total) $[9,10,19,20,22,27-29]$. The combination of both procedures is meant to correct both malalignment and patellar tilt, improving the patellofemoral contact pressure. Bellemans et al. reviewed 29 AMZ TTOs divided into two groups: with and without lateral release (performed in patients with patellar tilt angle larger than $8^{\circ}$ ). The authors concluded that TTO alone improved patellar subluxation, whereas the association of lateral release was also able to correct the patellar tilt [19].

There is little agreement in the literature regarding postoperative protocols. Most of the authors agreed that immediate full weight-bearing should be allowed with the knee in extension (e.g. brace, cast) [7-9,20, $23,26,29]$. Only in $30 \%$ of the cases, immediate full ROM was allowed, whereas in most of the knees (62.9\%), it was delayed at 4-8 weeks after surgery $[7,8,19,20,22,29]$. The weighted average length of immobilisation was less than 6 weeks ( 679 cases, 5.5 weeks), and it seems not to correlate with an increased risk of postoperative stiffness [10]. Despite the lack of evidence, a reasonable postoperative regimen seems to 


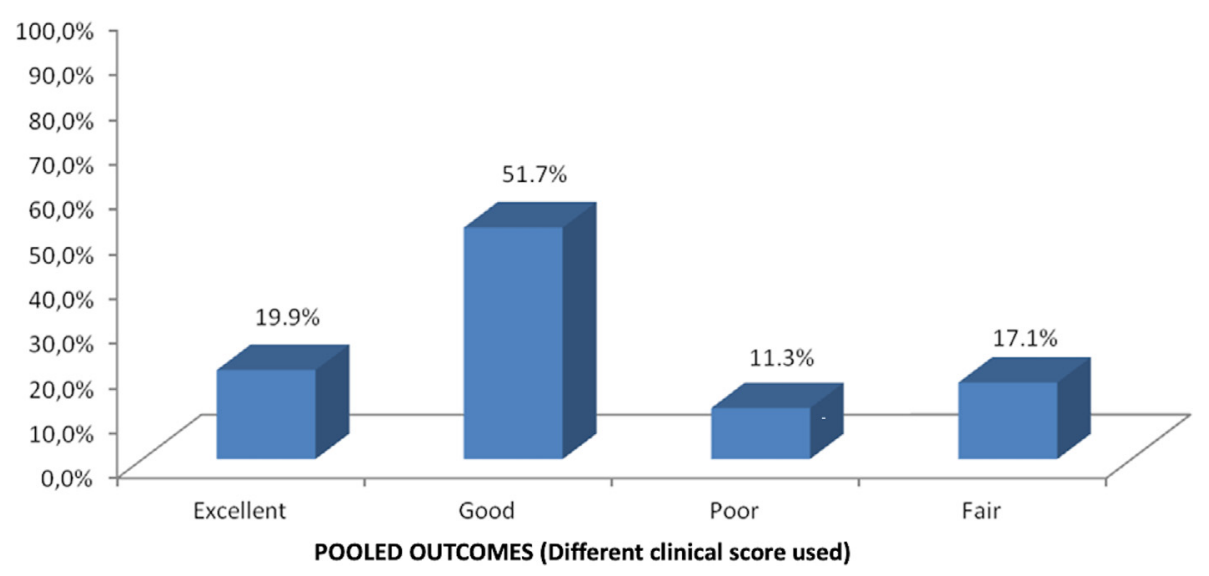

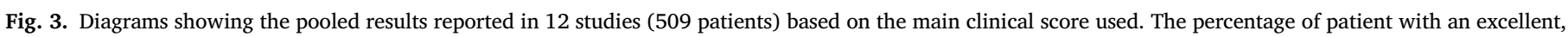
good, poor and fair results is reported.

include immediate weight-bearing with a hinged knee brace locked in extension (until radiographic evidence of bone healing, usually 5-6 weeks) and immediate passive ROM exercises $\left(0-90^{\circ}\right)$.

The fourth aim of the review was to evaluate the outcomes of TTO. There was no uniformity among the studies regarding the clinical scores used to evaluate the outcomes; for this reason, a meta-analysis of the data was not feasible. Twelve studies (509 knees) described the outcomes divided into subgroups based on the main score used [3,7,8,10,20,21, 24-28], with a weighted average of good/excellent results of $78.7 \%$. The rate of good/excellent results seemed to be higher in the AMZ group (79.8\%) than the pure anteriorisation group (73\%), but the two groups were heterogeneous. Few studies evaluated the prognostic factors related to TTO outcomes [7-10]. Jenny et al., in a series of 100 Maquet procedures, found no correlation between outcomes and age, sex, weight, duration of symptoms, preoperative pain or preoperative joint space narrowing [8]. Jack et al. in a series of 52 AMZ TTOs concluded that young age and lower preoperative Kujala score were related to better outcomes [7]. Wang et al. noted that unsatisfied patients were more likely to have severe articular degeneration [10]. Furthermore, the authors of this systematic review also published a series of 78 AMZ TTOs evaluating different prognostic factors possibly related to poor outcomes. They concluded that worse outcomes were associated with age $>45$ years, increased femoral anteversion, increased foot pronation and persistence of postoperative crepitus [9].

The last aim of the review was to evaluate the complication and failure rates associated with TTO. Only three studies omitted complications $[18,27,28]$. In the remaining studies (830 knees), 82 complications were reported (9.9\%), with stiffness and infection being the more common. The average rate of skin necrosis was $3.6 \%$ of all complications and was described only with pure anteriorisation TTOs [3,21]. Eight studies (323 knees) described a 44\% (range 11.6\%-96\%) average rate of hardware removal because of pain/discomfort when kneeling [7,9,10,22,23, 26-28]. Only four studies in this systematic review reported the failure rates, defined as the indication for patellectomy, patellofemoral replacement, TTO revision or need for total knee arthroplasty $[9,20,22$, $24,25]$. The total number of knees included in these studies was 194 (21.7\% of total), and 12 failures were reported, for a weighted failure rate of $6.2 \%$. This seems lower compared with the $30 \%-70 \%$ failure rates reported in other nonsystematic reviews $[10,13,33]$. However, this can be because of different definitions of failure (unsatisfactory outcomes versus need for surgical revision).

This review has some limitations mainly related to the low level of evidence of the included studies. There was a great variability in terms of indication, clinical scores used for the outcomes, and so further statistical analyses were not possible. In addition, determining the failure rate was difficult because only three studies defined and reported failures. On the other side, the lack of uniformity and low quality of the included studies is representative of the difficulties in treating this pathology and the need for higher quality studies to support any decision about surgical treatment in these patients.

In conclusion, this systematic review is a good overview of the existing literature on TTO and PFP associated with chondral disease. Variety of indication, clinical and radiological evaluation and scoring system used to evaluate outcomes may reflect the difficulties in treating this pathology, particularly in the past.

\section{Ethics approval and consent to participate}

Systematic Review, Not applicable.

\section{Consent for publication}

Not applicable.

\section{Availability of data and material}

All data and material regarding the study are available at the corresponding author.

\section{Authors' contributions}

$\mathrm{F} . \mathrm{R}=$ conceptualisation, data curation, formal analysis, methodology, and writing the original article. R.R. contributed to conceptualisation, supervision, and validation. U.C $=$ data curation, investigation, methodology, and writing the original draft. D.E.B = supervision and reviewing and editing the article.

\section{Funding}

Not applicable.

\section{Competing interests}

R.R. is a teaching consultant for Arthrex ${ }^{\circledR}$, Zimmer Biomet ${ }^{\circledR}$, Depuy Mitek ${ }^{\circledR}$, Medacta $\AA$, Lima Corporate ${ }^{\circledR}$ and Smith and Nephew ${ }^{\circledR}$. D.E.B. is a paid teaching consultant for Arthrex and Zimmer Biomet. He received editorial royalties for Elsevier and Springer, and he is in the editorial board "The Knee" journal, Elsevier. The other authors certify that they have no commercial associations that might pose a conflict of interest in connection with the submitted article. Conflict of interest is described in the appropriate uploaded document. 


\section{Acknowledgements}

Not applicable.

\section{References}

[1] Petersen W, Ellermann A, Gösele-Koppenburg A, et al. Patellofemoral pain syndrome. Knee Surg Sports Traumatol Arthrosc 2014;22(10):2264-74. https:// doi.org/10.1007/s00167-013-2759-6.

[2] Weinstein RN, Buuck DA, Fulkerson JP. Correlation of patellar articular lesions with results from anteromedial tibial transfer. Am J Sports Med 1997;25(4):533-7. https://doi.org/10.1177/036354659702500417.

[3] Maquet P. Advancement of the tibial tuberosity. Clin Orthop Relat Res 1976;(115): 225-30. pmid: 1253488.

[4] Cox JS. Evaluation of the Roux-Elmslie-Trillat procedure for knee extensor realignment. Am J Sports Med 1982;10(5):303-10. https://doi.org/10.1177/ 036354658201000509.

[5] Fulkerson JP. Anteromedialization of the tibial tuberosity for patellofemoral malalignment. Clin Orthop Relat Res 1983;(177):176-81. pmid: 6861394.

[6] Farr J. Autologous chondrocyte implantation improves patellofemoral cartilage treatment outcomes. Clin Orthop Relat Res 2007;463:187-94. pmid: 17960681.

[7] Jack CM, Rajaratnam SS, Khan HO, Keast-Butler O, Butler-Manuel PA, Heatley FW. The modified tibial tubercle osteotomy for anterior knee pain due to chondromalacia patellae in adults: a five-year prospective study. Bone Joint Res 2012;1(8):167-73. https://doi.org/10.1302/2046-3758.18.2000083.

[8] Jenny JY, Sader Z, Henry A, Jenny G, Jaeger JH. Elevation of the tibial tubercle for patellofemoral pain syndrome. An 8- to 15-year follow-up. Knee Surg Sports Traumatol Arthrosc 1996;4(2):92-6. https://doi.org/10.1007/BF01477260.

[9] Rosso F, Rossi R, Governale G, et al. Tibial tuberosity anteromedialization for patellofemoral chondral disease: prognostic factors. Am J Sports Med 2017;45(7): 1589-98. https://doi.org/10.1177/0363546517690387.

[10] Wang C-J, Wong T, Ko J-Y, Siu K-K. Triple positioning of tibial tubercle osteotomy for patellofemoral disorders. Knee 2014;21(1):133-7. https://doi.org/10.1016/ j.knee.2012.10.027.

[11] Johnson AA, Cosgarea AJ, Wolfe EL. Complications of tibial tuberosity osteotomy. Sports Med Arthrosc Rev 2017;25(2):85-91. https://doi.org/10.1097/ JSA.0000000000000151.

[12] Payne J, Rimmke N, Schmitt LC, Flanigan DC, Magnussen RA. The incidence of complications of tibial tubercle osteotomy: a systematic review. Arthroscopy 2015; 31(9):1819-25. https://doi.org/10.1016/j.arthro.2015.03.028.

[13] Engebretsen L, Svenningsen S, Benum P. Advancement of the tibial tuberosity for patellar pain. A 5-year follow-up. Acta Orthop Scand 1989;60(1):20-2. https:// doi.org/10.3109/17453678909150083.

[14] Maugans CJ, Scuderi MG, Werner FW, Haddad SF, Cannizzaro JP. Tibial tubercle osteotomy: a biomechanical comparison of two techniques. Knee 2017;24(2): 264-70. https://doi.org/10.1016/j.knee.2016.11.013.

[15] Saltzman BM, Rao A, Erickson BJ, et al. A systematic review of 21 tibial tubercle osteotomy studies and more than 1000 knees: indications, clinical outcomes, complications, and reoperations. Am J Orthop (Belle Mead NJ) 2017;46(6): E396-407. pmid: 29309452.

[16] Coleman BD, Khan KM, Maffulli N, Cook JL, Wark JD. Studies of surgical outcome after patellar tendinopathy: clinical significance of methodological deficiencies and guidelines for future studies. Victorian Institute of Sport Tendon Study Group. Scand J Med Sci Sports 2000;10(1):2-11. https://doi.org/10.1034/j.16000838.2000.010001002.x.

[17] Wright JG, Swiontkowski MF, Heckman JD. Introducing levels of evidence to the journal. J Bone Joint Surg Am 2003;85(1):1-3. pmid: 12533564.

[18] Koëter S, Diks MJF, Anderson PG, Wymenga AB. A modified tibial tubercle osteotomy for patellar maltracking: results at two years. J Bone Joint Surg Br 2007; 89(2):180-5. https://doi.org/10.1302/0301-620X.89B2.18358.

[19] Bellemans J, Cauwenberghs F, Witvrouw E, Brys P, Victor J. Anteromedial tibial tubercle transfer in patients with chronic anterior knee pain and a subluxation-type patellar malalignment. Am J Sports Med 1997;25(3):375-81. https://doi.org/ $10.1177 / 036354659702500318$.

[20] Cameron HU, Huffer B, Cameron GM. Anteromedial displacement of the tibial tubercle for patellofemoral arthralgia. Can J Surg 1986;29(6):456-8. pmid: 3779552.

[21] Karlsson J, Lansinger O, Swärd L. Anterior advancement of the tibial tuberosity in the treatment of the patellofemoral pain syndrome. Arch Orthop Trauma Surg 1985; 103(6):392-5. https://doi.org/10.1007/BF00435447.

[22] Liu JN, Wu H-H, Garcia GH, Kalbian IL, Strickland SM, Shubin Stein BE. Return to sports after tibial tubercle osteotomy for patellofemoral pain and osteoarthritis. Arthroscopy 2018;34(4):1022-9. https://doi.org/10.1016/j.arthro.2017.09.021.

[23] Morshuis WJ, Pavlov PW, de Rooy KP. Anteromedialization of the tibial tuberosity in the treatment of patellofemoral pain and malalignment. Clin Orthop Relat Res 1990;(255):242-50. pmid: 2347158.

[24] Pan HQ. Long-term follow-up study on the Maquet procedure with special reference to the causes of failure. Clin Orthop Relat Res 1993;(290):253-8. pmid: 8472456.

[25] Fulkerson JP, Becker GJ, Meaney JA, Miranda M, Folcik MA. Anteromedial tibial tubercle transfer without bone graft. Am J Sports Med 1990;18(5):490-6. https:// doi.org/10.1177/036354659001800508. discussion 496-497.

[26] Hejgaard N, Watt-Boolsen S. The effect of anterior displacement of the tibial tuberosity in idiopathic chondromalacia patellae: a prospective randomized study. Acta Orthop Scand 1982;53(1):135-9. https://doi.org/10.3109/ 17453678208992191.

[27] Sakai N, Koshino T, Okamoto R. Pain reduction after anteromedial displacement of the tibial tuberosity: 5-year follow-up in 21 knees with patellofomoral arthrosis. Acta Orthop Scand 1996;67(1):13-5. https://doi.org/10.3109/ 17453679608995601.

[28] Shelbourne KD, Porter DA, Rozzi W. Use of a modified Elmslie-Trillat procedure to improve abnormal patellar congruence angle. Am J Sports Med 1994;22(3):318-23. https://doi.org/10.1177/036354659402200304.

[29] Ferguson Jr. AB. Elevation of the insertion of the patellar ligament for patellofemoral pain. J Bone Joint Surg Am 1982;64(5):766-71. pmid: 7085703.

[30] Lysholm J, Gillquist J. Evaluation of knee ligament surgery results with special emphasis on use of a scoring scale. Am J Sports Med 1982;10(3):150-4. https:// doi.org/10.1177/036354658201000306.

[31] Kujala UM, Jaakkola LH, Koskinen SK, Taimela S, Hurme M, Nelimarkka O. Scoring of patellofemoral disorders. Arthroscopy 1993;9(2):159-63. https://doi.org/ 10.1016/s0749-8063(05)80366-4.

[32] Tompkins M, Arendt EA. Complications in patellofemoral surgery. Sports Med Arthrosc Rev 2012;20(3):187-93. https://doi.org/10.1097/JSA.0b013e31825c74cf.

[33] McCarthy MM, Strickland SM. Patellofemoral pain: an update on diagnostic and treatment options. Curr Rev Musculoskelet Med 2013;6(2):188-94. https:// doi.org/10.1007/s12178-013-9159-x. 